\title{
Integration of PV systems into low voltage networks using standard load profiles
}

\author{
M. Eisenreich ${ }^{1}$, G. Balzer ${ }^{1}$, J. Backes ${ }^{2}$ and B. Maurer ${ }^{2}$ \\ ${ }^{1}$ Technische Universität Darmstadt \\ Institute of Electrical Power Systems \\ Landgraf-Georg-Str. 4, 64283 Darmstadt (Germany) \\ Phone number: +49 6151 16-6587, Fax number: +49 6151 16-4259 \\ E-mail: marc.eisenreich@eev.tu-darmstadt.de, gerd.balzer@eev.tu-darmstadt.de \\ ${ }^{2}$ EnBW Regional AG \\ Kriegsbergstr. 32, 70174 Stuttgart (Germany) \\ Phone: +49 711 128-3203, Fax number: +49 711 128-3176 \\ E-mail: j.backes@enbw.com, bernd.maurer@enbw.com
}

\begin{abstract}
The impact of a higher share of distributed generation units is shown using the example of PV systems. A LV network with partly meshed and partly radial topology has been examined. Standard load profiles have been applied to obtain results with a resolution of 15 minutes. Feed-in profiles are compared with a data set based on measured values to model PV generation. Two extreme cases for transformer loading and compliance with voltage limits are high load (winter) without PV and low load (summer) with PV feed-in. In the latter case, power flow via the transformer was reversed during certain periods of the day. At the same time, voltage was increased especially at a long electrical distance from the transformer.
\end{abstract}

\section{Key words}

Distributed generation, low voltage network, load flow modelling, load profiles, voltage limit

\section{Introduction}

The landscape of transmission and distribution of electrical energy is expected to undergo significant changes in the future. One challenge arises from a decreasing level of centralisation of generation units which results inherently from a growing share of renewable energy or combined heat and power stations. To a large extent, these units are connected to the low voltage network, thus close to consumption. However, at the design state of the current grid, mainly load and load forecasts were considered relevant. Given the technological progress, installed power of new distributed generation (DG) units can exceed consumption. This effect is particularly visible for photovoltaic (PV) systems as peak generation is in the middle of the day, while peak consumption occurs mainly in the evening. Several studies have been carried out, naming exemplarily one focussing on the medium voltage network [1] or on a housing area generating a surplus supply of energy [2]. Within this paper, the approach has been chosen to investigate a real low voltage network equipped with PV installations by means of load flow analysis with standard load profiles. The aim is to investigate the impact on active power exchange via the transformer as well as on possible violation of voltage limits.

\section{Models}

Following models have been used to simulate the network, the household customers and the PV units. All investigations have been carried out with a commercial software system for network planning.

\section{A. Network}

The research for this paper is based on one low voltage (LV) network covering several streets of a small town in Germany. It is part of a medium voltage (MV) network ranging over a mainly rural area. The LV network consists of 81 household loads and 4.1 kilometres of lines where only one third is implemented as cable. The annual peak power amounts to $274 \mathrm{kVA}$ which corresponds to $68 \%$ loading of the $400 \mathrm{kVA}$ distribution transformer. Approximately half of the loads are connected in a meshed structure; the rest is connected in a radial structure to the substation. Fig. 1 shows the LV network topology with its 5 feeders and 81 loads. 


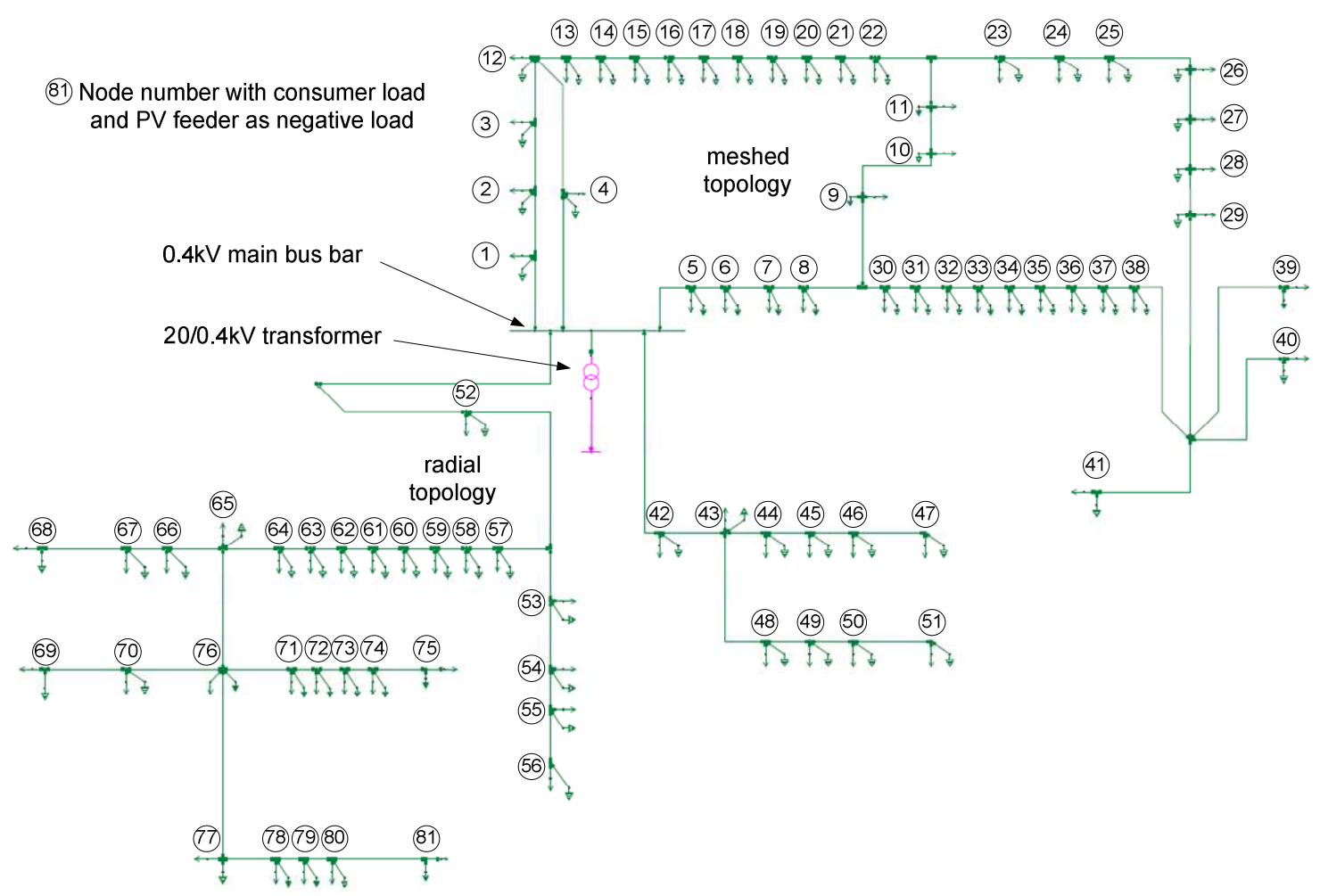

Fig. 1: LV network with its 5 feeders and 81 loads

\section{B. Consumers}

In this model, loads represent household customers. Due to the lack of additional information, they are all assumed equal concerning peak power and load profile.

This investigation shall be carried out using standard load profiles (SLP) [3]. They consist of a set of daily load curves with a resolution of 15 minutes, i.e. 96 values per day. One profile comprises nine different curves, considering three seasons (winter, summer, transition period) as well as three day types (weekday, Saturday, Sunday). These SLPs are designed for different types of customers, namely households, agriculture and commerce/industry, and eventual sub-types. In the present LV network, only the household profile $\mathrm{H} 0$ is considered. Apart from the day type, this profile uses a correction factor for each day according to the season [4]. Its value oscillates roughly between 1.25 in winter and 0.75 in summer. This leads to smoother transitions between seasons. The raw form of SLPs is standardised to a yearly consumption of 1000 kilowatt-hours $(\mathrm{kWh})$, corresponding to the area underneath the 365 daily load curves. From this and the known maximum load follows that the $\mathrm{H} 0$ profile has an utilisation factor of 0.43 as the share of the maximum load in the constant load. This value is in line with the provided network data.

In the given network, not the yearly consumption, but the peak power of the substation is known by measurement. It is divided by the number of connected consumers to obtain peak power at household level. Power factor is considered constant over all households with 0.95 inductive. Hence, all 81 customers are assumed to follow exactly the same load curve. Consequently, the real peak values of each single customer are not known. However, this is not a problem because they don't appear at the same point in time. The more customers are grouped, the more the collective curve is flattened. Finally, the values of the household load profile $\mathrm{H} 0$ are normalised so that its maximum value equals to the peak power of one household. Fig. 2 shows the load profile to be used in the following simulations for each household customer.

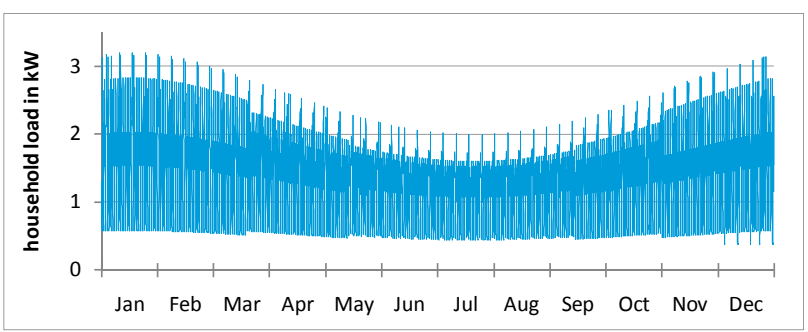

Fig. 2: load profile H0 adapted to the simulated network

\section{PV units}

This paper aims to represent a possible future state of the network. Therefore, the potential for PV systems in the given area has been estimated. Knowing the names of the town and the streets, satellite images of the roofs provide a sufficient accuracy. An average roof size as well as the number of south-oriented houses has been determined. Common values for installed capacity per surface have been considered. Relating this to the number of inhabitants, it can be concluded that the potential for PV installations is approximately one kilowatt-peak $(\mathrm{kWp})$ per inhabitant for the respective town. The yearly output has been estimated according to measured values of solar irradiation and the system efficiency. A comparison with 
actually operating PV units in this area proves the plausibility. Using cautious assumptions, for the following simulations, a PV system with $10 \mathrm{kWp}$ is installed on every second roof obtaining a yearly output of $900 \mathrm{kWh}$ per $\mathrm{kWp}$ and year. Only active power feed-in is considered, i.e. the power factor equals to 1 .

\section{1) Feed-in profile}

PV units are connected to the system similar to loads, but with opposite sign. Hence, profiles can be used in a comparable way. A feed-in profile is available from the distribution network operator [5]. Like the SLPs, raw data is standardised to $1000 \mathrm{kWh}$ energy per year. It consists of twelve different curves, one for each month. Obviously, considering each single day of one month in equal measure conceals the real peak values of sunny days as they are compensated by cloudy days. Fig. 3 shows the feed-in profile for a PV system of $10 \mathrm{kWp}$, corresponding to an energy of $9000 \mathrm{kWh}$ per year. Unlike household loads, PV feed-in appears highly synchronously as it does not depend on consumer habits, but on the weather. Therefore, the exact knowledge of generation peak values might be indispensable.

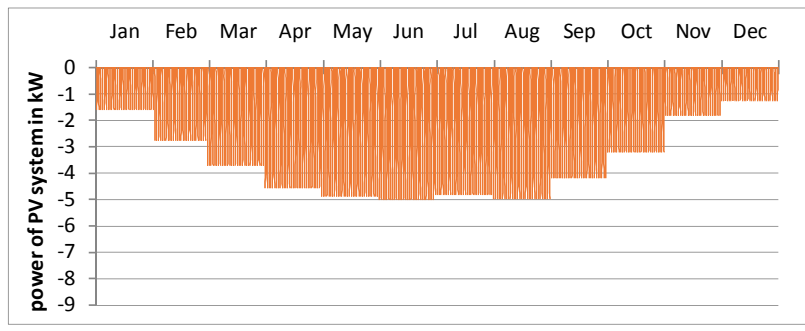

Fig. 3: PV generation using a standard feed-in profile

\section{2) Measured values (ungrouped)}

Alternatively, measured values can be used without grouping them into day profiles. Hence, the generation curve of every calendar day is unique. This approach has been carried out to create a reference result. The used data set is based on measured global irradiation values originating from a test facility in the area of the investigated town [6]. After averaging several years, data is furthermore corrected by modeling the position of the sun. Assuming system losses of $15 \%$, the resulting data set consists of one single curve of about 35000 quarterhourly values for one whole year. Fig. 4 shows the resulting feed-in curve, again normalised to $9000 \mathrm{kWh}$ energy per year. In the following chapter, differences between both approaches are highlighted.

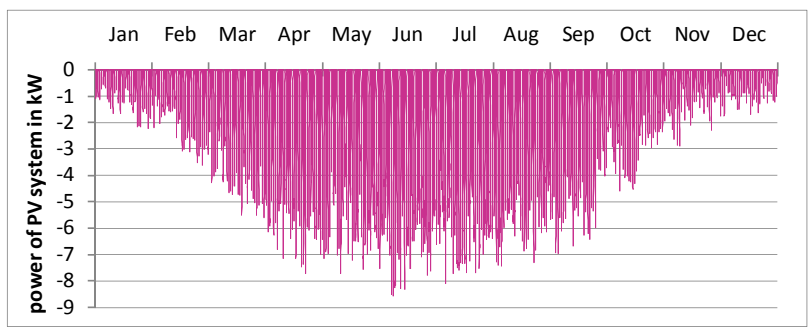

Fig. 4: PV generation using adapted measured values

\section{Results}

Several simulations were carried out in order to compare different situations. Assuming a given household demand, installed PV capacity is varied from zero to the half $(5 \mathrm{kWp})$ and then to the entire $(10 \mathrm{kWp})$ estimated maximum potential. The impact on the system, especially the loading of critical components like cables or transformers, as well as possible voltage violations due to PV generation has been examined. The graphs presented in this paper show the third weekend in January and the second weekend in June as they comprise the value of maximum household consumption and maximum PV feed-in, respectively. All subsequent figures show the results in winter in the upper part and the results in summer in the lower part for Friday, Saturday and Sunday.

\section{A. Loading and inverse power flow}

Current, power flow and loading of the transformer and cables have been simulated. The most particular phenomenon is the reversal of active power flow in case of significant PV feed-in. Therefore, in the following figures only active power flow is presented. Furthermore, it can be said that loading of cables has not been critical during the simulation; that is why it is not detailed.

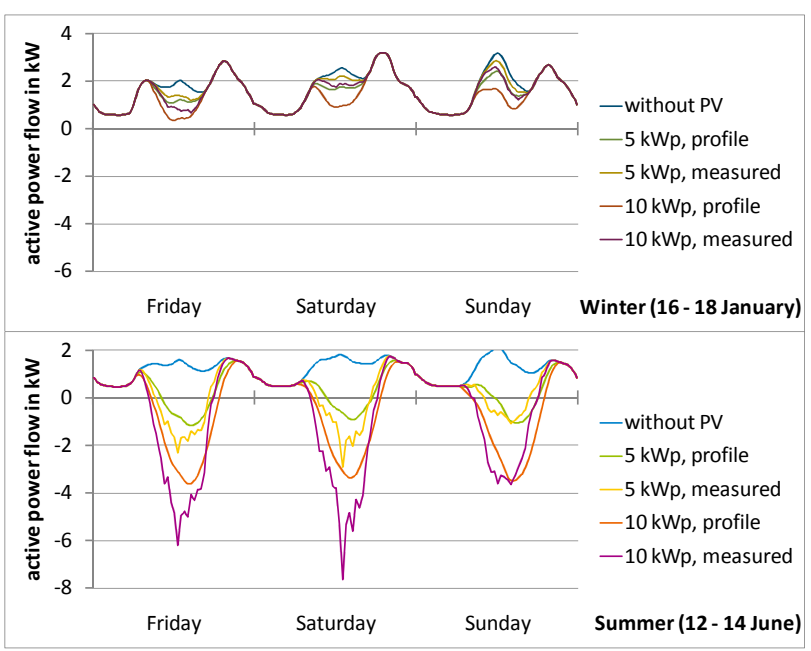

Fig. 5: active power flow from node 80 to 81

Fig. 5 shows the active power flow towards the last node in a branch of the radial structure. Hence, this is nothing else than the superposition of the above-mentioned load and feed-in profiles. It can be seen that the power flow is reduced in the middle of the day in winter. In summer, it is reversed in all four feed-in scenarios. Furthermore, the feed-in curve resulting from measured values lies above the corresponding profile in winter, and below in summer. Especially in summer, the difference is remarkable and shows that single peaks can have double magnitude of the average peak. It is also clearly visible that each day of the measured curve is different.

When regarding a cable within the meshed topology (see Fig. 6) the level of active power flow is generally higher as more than one load are connected via that cable. 
Another effect is that the fluctuation range is smaller. Consequently, power flow reversal can be observed only rarely within a meshed structure. But the discrepancy between measured values and profile does not decline significantly.

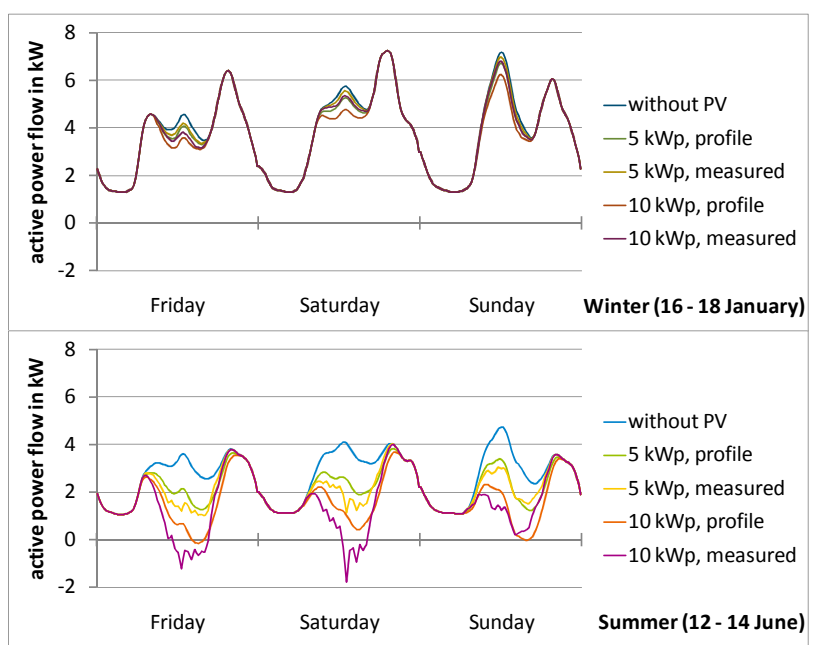

Fig. 6: active power flow from node 28 to 29

Finally, the power exchange with the overlying MV network is described. It is the summation of all flows to and from all the loads, and therefore of similar shape. Peak demand in January and in absence of any PV units rises above $250 \mathrm{~kW}$ (see Fig. 7). PV installations contribute to decrease the noon and afternoon peaks already in winter. With lower energy demand and at the same time higher PV supply (summer season), current and power flow via the transformer do not only decrease, but also change direction. In June with an assumed maximum PV feed-in, the peak power is reduced by approx. the half. Moreover, a negative peak occurs during noon. This phenomenon needs to be taken into account when adapting the protection system. Also for the transformer, overloading is not an issue; even during reverse power flow, nearly half of the capacity is still available.

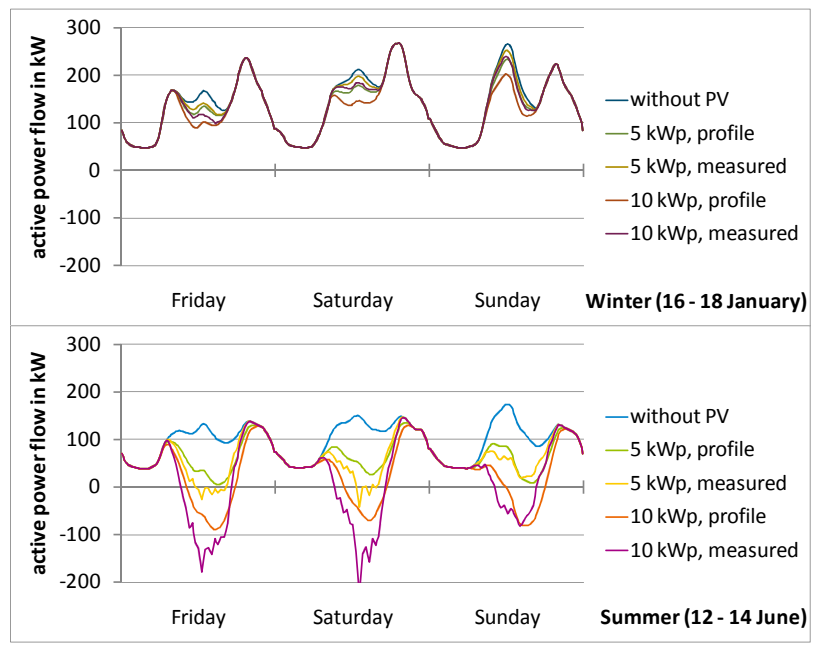

Fig. 7: active power flow into LV grid (via transformer)

\section{B. Voltage limits}

In order to present characteristic voltage profiles, the nodes 29 and 81 have been selected for connecting the most distant load in the meshed and the radial topology, respectively. Furthermore, the $0.4 \mathrm{kV}$ main bus bar (connected to the transformer) is selected because its voltage profile is mainly imposed by the MV level where no PV feed-in is considered. The scale of the figure has been chosen in a way to make the node voltages better comparable to each other because they differ mainly regarding the amplitude whereas the profile itself is quite similar.

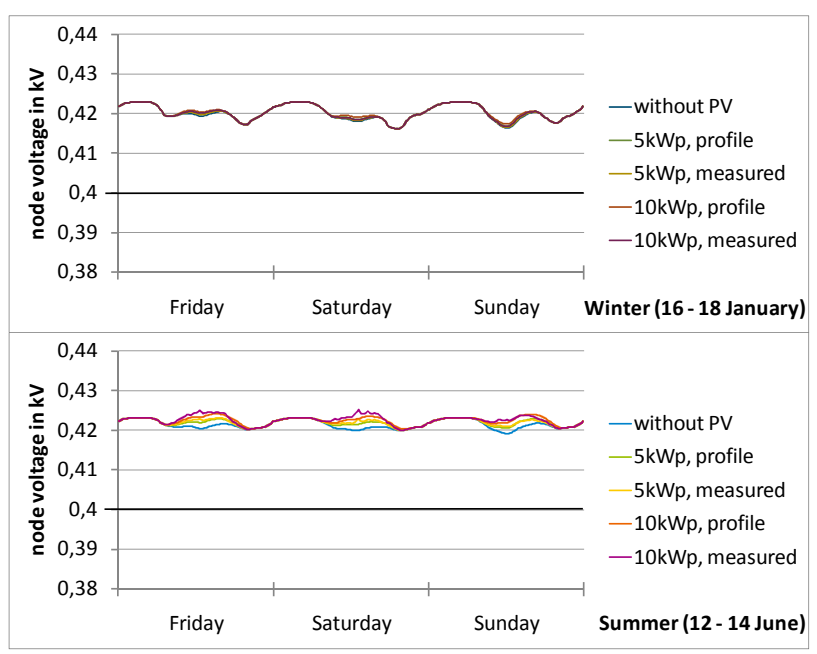

Fig. 8: voltage profiles for $0,4 \mathrm{kV}$ main bus bar

Fig. 8 shows the rather weak voltage oscillations at transformer level which result from the impedance of the overlying MV network. Voltage is lowest during evening consumption peaks and highest during night. In winter, PV feed-in has nearly no effect on voltage. In summer, a slight increase in voltage can be observed which exceeds slightly the former maximum during night.

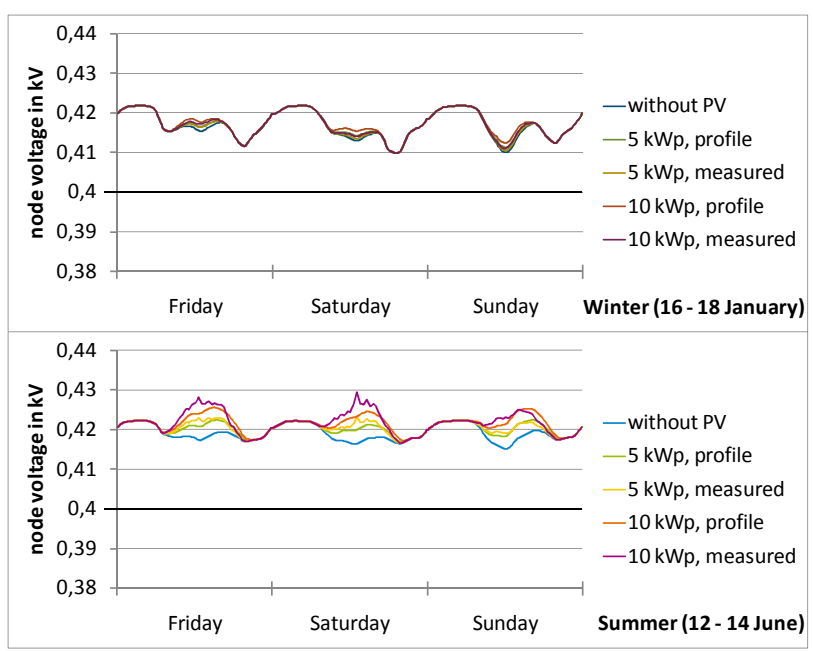

Fig. 9: voltage profiles for node 29 (meshed part)

Comparing node 29 (see Fig. 9) to the main bus bar does not reveal big differences in winter except a more distinctive voltage drop in the evening hours. However, 
in the summer week, the four different curves for considering PV feed-in are distinguishable, obviously during day-time when PV feed-in occurs. Comparing the two curves obtained via feed-in profile, it can be seen that the rise in voltage is proportional to the PV generation.

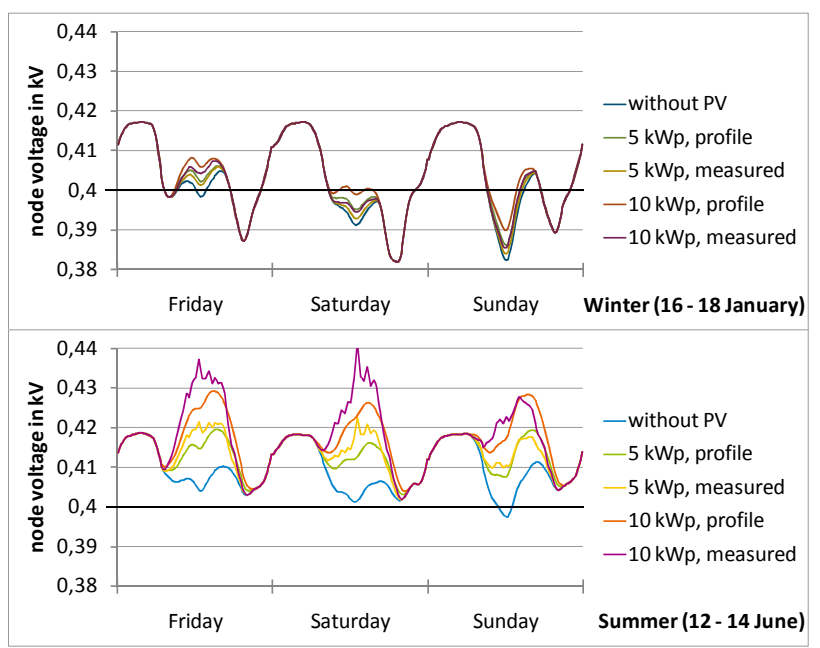

Fig. 10: voltage profiles for node 81 (radial part)

When looking at the far situated node 81 (see Fig. 10), the abovementioned effects are more or less amplified. In winter, voltage oscillations cover a larger span, between $380 \mathrm{~V}$ and $420 \mathrm{~V}$, which also implies a generally lower voltage at this node. However, PV feed-in only contributes to raise voltage during afternoons, but always within the above mentioned range. Also in summer, the general voltage level is lower than for node 29 , between $400 \mathrm{~V}$ and $420 \mathrm{~V}$ without PV. But already $5 \mathrm{kWp}$ installed PV capacity on every second roof causes a voltage increase above $420 \mathrm{~V}$ during the afternoon. Remarkable is also the gap between the curves based on generation profiles and measured values, respectively. As can be seen in Fig. 3 and Fig. 4, the measured generation peak of sub-section 2.C.2) is 1.7 times higher than the profile value of sub-section 2.C.1), which leads to a difference of the respective node voltage of up to $15 \mathrm{~V}$. However, the standard limit of $400 \mathrm{~V}+/-10 \%$ is not violated.

To conclude this part, one observation can be made regarding the network topology. Radial networks seem to be more susceptible to voltage level problems. The reason is that the electrical distance, i.e. the total impedance between transformer and load, is generally higher at the end of radial network than in the middle of a ring. However, the topology is not the only relevant aspect. Type of the line as well as their length has an impact on the electrical distance as well.

\section{Conclusion}

Standard load profiles are a promising way to investigate the impact of distributed generation systems on an existing grid. With a resolution of 15 minutes, they allow detailed load flow simulations to study the development of characteristic parameters in the course of one day.

Given the fulfilment of the assumption concerning density of future PV installation, one important result is that active power exchange with the MV network will be reversed during sunny days, amplified by low consumption. In this network, the transformer's rated power is sufficient. But the results for transformer loading depend on the way generation data is entered into the simulation programme. Due to the simultaneous occurrence of PV generation in the same area, a data set of measured feed-in values considers power peaks in a more realistic manner than monthly profiles could do.

Basically, the same applies to household load profiles even though the simultaneousness of consumption is lower and thus less problematic. A standard profile can provide only average information. Thus, the higher the aggregation level, the better it fits reality. It cannot be interpreted as the load curve of one single household. If this is desired, other kinds of profiles have to be developed to obtain a heterogeneous group of consumers.

\section{References}

[1] T. Yebra, V. Fuster, A. Quijano and P. Llovera, "DG integration limits in distribution networks" in ICREPQ 09 Valencia, 2009

[2] M. Petit, Xavier Le Pivert and A. Guiavarch, "Impact of Plus Energy Buildings on the voltage profile of the distribution networks" CIRED Seminar 2008: SmartGrids for Distribution, Frankfurt 2008

[3] B. Schieferdecker, C. Fünfgeld, H. Meier and T. Adam: Repräsentative VDEW-Lastprofile, Frankfurt, 1999 , VDEW-Materialien M-28/99

[4] C. Fünfgeld and R. Tiedemann, Anwendung der Repräsentativen VDEW-Lastprofile step-by-step, Frankfurt, 2000, VDEW-Materialien M-05/2000

[5] EnBW Einspeiseprofile gültig ab 1. August 2006, url: http:// www.enbw.com/content/de/netznutzer/stromverteilnetz/netz nutzung/lastprofile/index.jsp; access date: 30 October 2009

[6] M. Fleckenstein, J. Wolf and T. Hartkopf, „Nachführstrategien für dachparallele Vakuumröhrenkollektoren“ thesis paper at TU Darmstadt, Darmstadt, 2009 